\title{
Grain size effect on multiple-stage transformations of a cold-rolled and annealed equiatomic TiNi alloy
}

\author{
S.H. Chang ${ }^{\text {a }}$, S.K. Wu ${ }^{\text {a,b,* }}$, G.H. Chang ${ }^{b}$ \\ a Department of Materials Science and Engineering, National Taiwan University, 1, Roosevelt Rd., Sec. 4, Taipei 106, Taiwan, ROC \\ ${ }^{\mathrm{b}}$ Department of Mechanical Engineering, National Taiwan University, Taipei 106, Taiwan, ROC
}

Received 8 November 2004; received in revised form 30 January 2005; accepted 7 February 2005

Available online 2 March 2005

\begin{abstract}
$\mathrm{Ti}_{50} \mathrm{Ni}_{50}$ shape memory alloy cold-rolled and annealed at specific conditions can exhibit a four-stage martensitic transformation. There are two small and two large peaks which are associated with the $\mathrm{B} 2 \rightarrow \mathrm{R} \rightarrow \mathrm{B} 19^{\prime}$ transformations of large grains in the specimen center and that of small grains near the rolling surface, respectively.
\end{abstract}

(C) 2005 Acta Materialia Inc. Published by Elsevier Ltd. All rights reserved.

Keywords: Shape memory alloy; Martensitic transformation; Cold working; Annealing; Differential scanning calorimetry

\section{Introduction}

TiNi alloys are known as the most important shape memory alloys (SMAs), with good shape memory effect (SME), superelasticity (PE) and damping capacity (DC) [1]. It is well known that the martensitic transformation of an equiatomic TiNi alloy comprises a single-stage martensitic transformation from the parent B2 phase to the B19' martensite phase. After conducting a thermomechanical treatment or adding a third element, the transformation sequence can change into a twostage transformation, from B2 to premartensite R-phase and then to B19' upon cooling [2]. Recently, the martensitic transformation of Ni-rich TiNi SMAs was found to have more than two distinct steps, and is known as the multi-stage martensitic transformation (MST). Bataillard et al. [3,4] attributed the cause of MST to

\footnotetext{
${ }^{*}$ Corresponding author. Address: Department of Materials Science and Engineering, National Taiwan University, 1, Roosevelt Rd., Sec. 4, Taipei 106, Taiwan, ROC. Tel.: +886 22363 7846; fax: +88622363 4562.

E-mail address: skw@ntu.edu.tw (S.K.Wu).
}

the stress fields around coherently precipitated $\mathrm{Ti}_{3} \mathrm{Ni}_{4}$ particles. Khalil-Allafi et al. [5] found two distinct steps

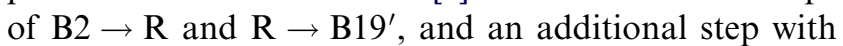
$\mathrm{B} 2 \rightarrow \mathrm{B} 19^{\prime}$ in the differential scanning calorimetry (DSC) cooling curves of aged Ni-rich TiNi alloys. They proposed that the MST comes from the inhomogeneous distribution of $\mathrm{Ti}_{3} \mathrm{Ni}_{4}$ precipitates.

$\mathrm{Su}$ and $\mathrm{Wu}[6]$ have obtained a complex four-stage MST in a $20 \%$ cold-rolled and annealed $\mathrm{Ti}_{49} \mathrm{Ni}_{51}$ alloy, and they suggested that the MST is the result of the combined effect of severe cold-working and long-time annealing. Kim et al. [7] reported a low temperature aging-induced two-stage R-phase transformation in $\mathrm{Ti}_{49.1} \mathrm{Ni}_{50.9}$ alloy, and they identified that the first $\mathrm{R}$ phase transformation was associated with precipitates while the second R-phase transformation could be attributed to matrix regions far from precipitates. According to the aforementioned studies, all the complex MSTs appear in Ni-rich TiNi alloys and have to do with heterogeneities caused by $\mathrm{Ti}_{3} \mathrm{Ni}_{4}$ precipitates. In this study, we find a four-stage MST in a cold-rolled and annealed $\mathrm{Ti}_{50} \mathrm{Ni}_{50}$ alloy. In the $\mathrm{Ti}_{50} \mathrm{Ni}_{50}$ alloy, neither $\mathrm{Ti}_{3} \mathrm{Ni}_{4}$ precipitation nor non-uniform precipitation 
distribution is observed in the specimen. The complex MST behavior discussed in this study was identified by DSC and dynamic mechanical analyzer (DMA) tests; microstructure evidence is provided to elucidate this uncommon four-stage MST.

\section{Experimental procedures}

An equiatomic $\mathrm{Ti}_{50} \mathrm{Ni}_{50}$ alloy was prepared by conventional vacuum arc remelting. The as-melted ingots were hot-rolled at $850{ }^{\circ} \mathrm{C}$ into $2 \mathrm{~mm}$ thick plates, and then the plates were solution-treated at $850^{\circ} \mathrm{C}$ for $2 \mathrm{~h}$ followed by quenching in water. The oxide layer of the solutiontreated plates was removed and the specimen thickness was reduced to $1.9 \mathrm{~mm}$. Thereafter, the plates were coldrolled along the hot-rolling direction at a rolling speed of $10 \mathrm{~m} / \mathrm{min}$. No annealing process was conducted during the cold-rolling to avoid the occurrence of recrystallization. The thickness of the plate decreased from $1.9 \mathrm{~mm}$ to $1.24 \mathrm{~mm}$ and reached a final $35 \%$ thickness reduction. Then the cold-rolled plates were cut into test specimens, sealed in an evacuated quartz tube and annealed at $500{ }^{\circ} \mathrm{C}$ and $650{ }^{\circ} \mathrm{C}$ in salt baths for different time intervals.

Transformation temperatures of cold-rolled and annealed specimens were determined by DSC tests using the TA Q10 DSC equipment at a constant cooling rate $\left(10^{\circ} \mathrm{C} / \mathrm{min}\right)$. Specimens for DMA experiments were cut in the direction along the rolling direction (RD). Tan $\delta$ was measured by TA 2980 DMA equipment using heating and cooling rates of $3{ }^{\circ} \mathrm{C} / \mathrm{min}$. The dimension of the specimens used in the DMA tests was $40 \times 5 \times 1.24 \mathrm{~mm}^{3}$, and the amplitude and frequency used were $2 \mu \mathrm{m}$ and $2 \mathrm{~Hz}$, respectively. The cross-sectional microstructures of the specimens were prepared by the normal metallographic procedures and then observed by a Nikon Microphoto-FXA optical microscope (OM). From the OM images, the average grain size of cold-rolled and annealed specimens was estimated by the linear intercept method [8]. Ten parallel straight lines along or normal to the rolling direction were used to count the number of grains intercepted and then the average was taken to quantify the average grain size.

\section{Experimental results}

\subsection{DSC and DMA measurements}

Fig. 1 shows the cold-rolled $\mathrm{Ti}_{50} \mathrm{Ni}_{50}$ alloy annealed at $500{ }^{\circ} \mathrm{C}$ for different time intervals. When the annealing time is short, as shown in Fig. 1(a) and (b), two peaks characterize the forward and reverse transformations. Upon increasing the annealing time to 1 and $3 \mathrm{~h}$, the transformation occurs in four stages on cooling, as shown in Fig. 1(c) and (d). After annealing for $24 \mathrm{~h}$, these four peaks combine and become two large peaks; and the two peaks in the reverse transformation after 1 and $3 \mathrm{~h}$ merge to one single large peak. The transformation behavior of Fig. 1 agrees with what has been reported on the transformation behavior of cold-rolled and annealed near equiatomic TiNi SMAs [9-11] except that the four-stage MST shown in Fig. 1(c) and (d) has never been reported before. As the annealing temperature is increased to $650{ }^{\circ} \mathrm{C}$ (not shown), the tendency of the transformation sequence is similar to that shown in Fig. 1. A four-stage MST also appears when the annealing is performed at $650{ }^{\circ} \mathrm{C}$ for $90 \mathrm{~s}$ and for longer annealing time these four peaks gradually merge to two peaks.

Fig. 2 shows DSC and DMA results of the cold-rolled specimen annealed at $500{ }^{\circ} \mathrm{C}$ for $3 \mathrm{~h}$. Fig. 2(a) shows the DSC curve of Fig. 1(d) and Fig. 2(b) indicates the corresponding DMA results for $\tan \delta$. As shown in Fig. 2(b), four transformation peaks which match the transformation peaks in DSC curve are observed; there is a small shift between the results of the two methods which is attributed to different cooling/heating rates and specimen sizes used in DSC and DMA testing. In addition
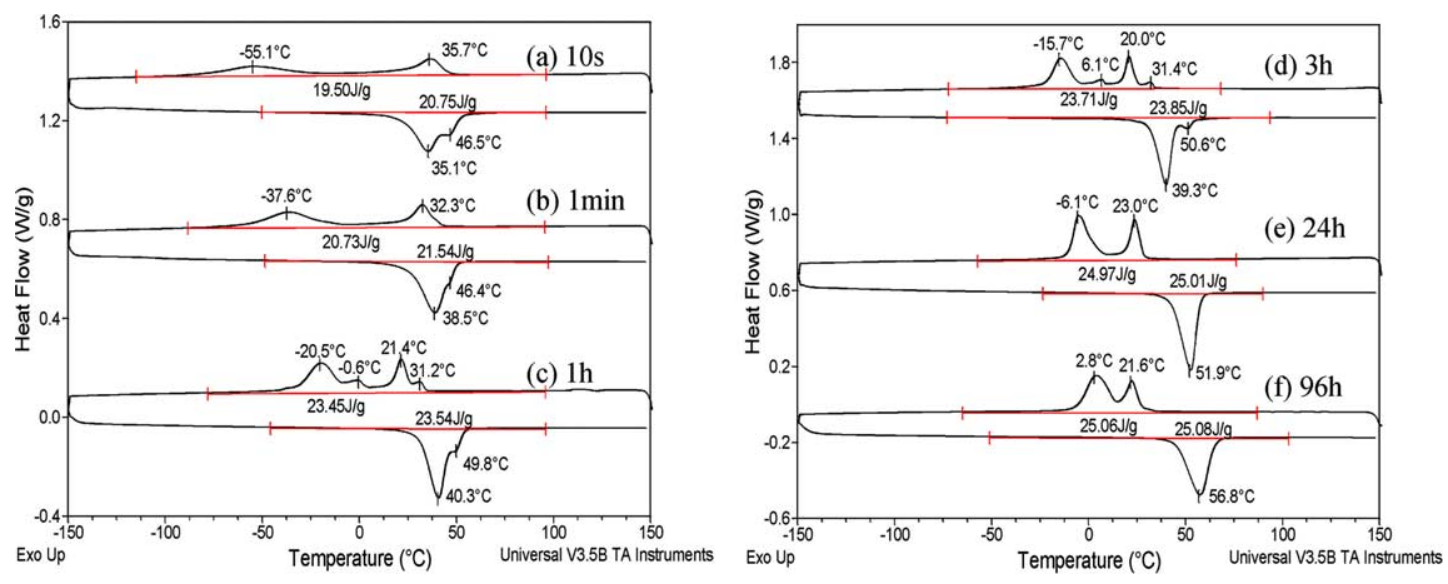

Fig. 1. DSC curves for cold-rolled $\mathrm{Ti}_{50} \mathrm{Ni}_{50}$ alloy annealed at $500{ }^{\circ} \mathrm{C}$ for different time intervals. 


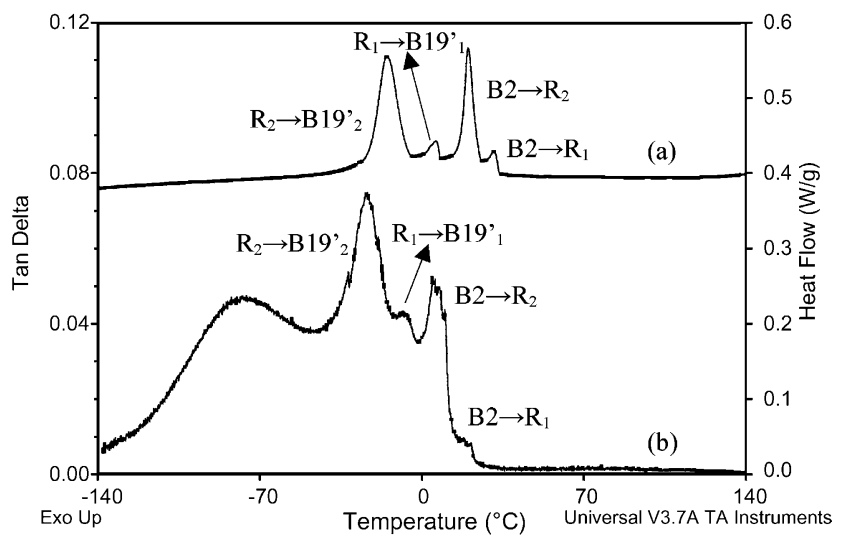

Fig. 2. (a) DSC and (b) DMA curves for cold-rolled $\mathrm{Ti}_{50} \mathrm{Ni}_{50}$ alloy annealed at $500{ }^{\circ} \mathrm{C}$ for $3 \mathrm{~h}$.

to the four transformation peaks which appear in the DSC tests, there is also one extra peak obtained at about $-75^{\circ} \mathrm{C}$ in Fig. 2(b). This peak was not observed in the DSC curve and is known as a relaxation peak [2].

\subsection{Microstructure observations}

Fig. 3 shows OM images of the cross-sectional microstructure of the cold-rolled $\mathrm{Ti}_{50} \mathrm{Ni}_{50}$ alloy with and without annealing at $500{ }^{\circ} \mathrm{C}$ for $3 \mathrm{~h}$. Fig. 3(a) illustrates the as cold-rolled $\mathrm{Ti}_{50} \mathrm{Ni}_{50}$ alloy and it can readily be noticed that the microstructure in the specimen center is quite different from that near the specimen's rolling surfaces. The grains in the specimen center are elongated along the RD and the average grain size is about
$40 \mu \mathrm{m}$. The grains near the rolling surfaces are fiberstructured and their grain boundaries are not well defined. This is because the two surfaces are in direct contact with the rollers and suffer more plastic deformation than the central region.

Fig. 3(b) shows the cross-sectional microstructure of the cold-rolled specimen annealed at $500{ }^{\circ} \mathrm{C}$ for $3 \mathrm{~h}$. Fig. 3(c) and (d) show the enlarged views of the regions at the center and near the rolling surface of Fig. 3(b), respectively. The average grain sizes calculated from Fig. 3(c) and (d) are about $70 \mu \mathrm{m}$ and $7 \mu \mathrm{m}$ in the RD and, $15 \mu \mathrm{m}$ and $7 \mu \mathrm{m}$ in its normal direction, respectively. Fig. 3(e) shows the microstructure of the coldrolled specimen annealed at $500{ }^{\circ} \mathrm{C}$ for $24 \mathrm{~h}$. From Fig. 3(e), the average grain sizes in the specimen center and near the rolling surface are calculated to be about $72 \mu \mathrm{m}$ and $53 \mu \mathrm{m}$ in RD and $17 \mu \mathrm{m}$ and $12 \mu \mathrm{m}$ in its normal direction, respectively. Here, the grain sizes in the center of the sheet and that near the rolling surface are approaching each other, i.e. the grain size distribution in the whole specimen becomes more uniform.

\section{Discussion}

\subsection{Identification of four-stage MST in a cold-rolled and annealed $\mathrm{Ti}_{50} \mathrm{Ni}_{50}$ alloy}

\subsubsection{DSC results}

Fig. 4 shows several partial DSC transformation cycles of the cold-rolled specimen annealed at $500{ }^{\circ} \mathrm{C}$ for $3 \mathrm{~h}$. There are four transformation peaks on cooling,

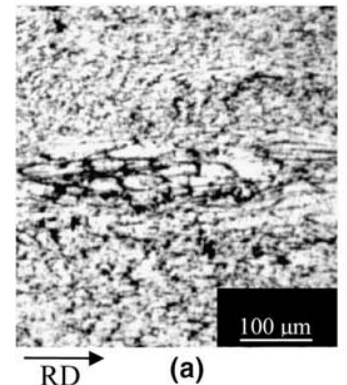

(a)

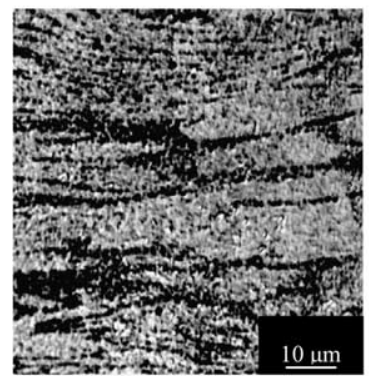

(c)

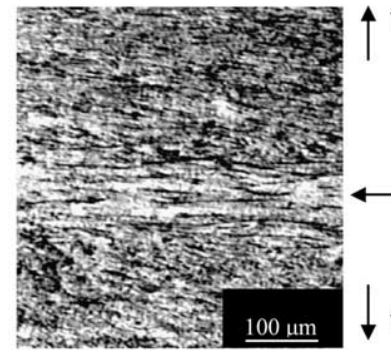

(b)

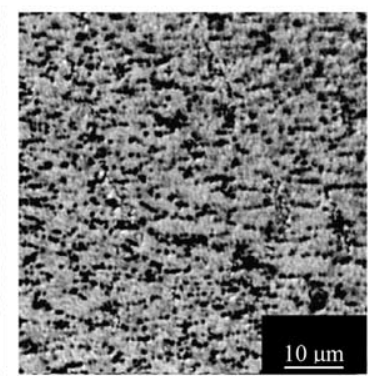

(d) to the specimen rolling surface

central region

to the specimen rolling surface

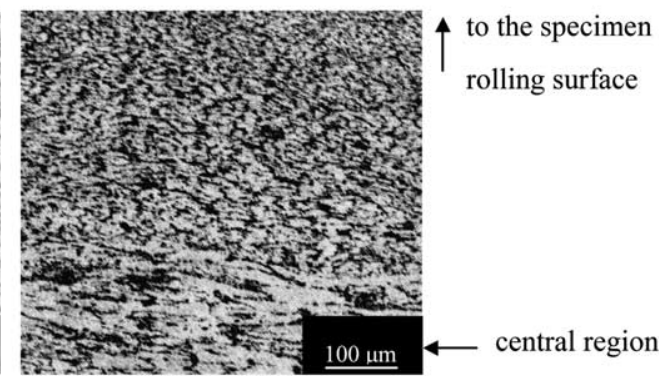

(e)

Fig. 3. OM micrographs of the cross-sections of the microstructure of cold-rolled $\mathrm{Ti}_{50} \mathrm{Ni}_{50}$ alloy with and without annealing: (a) as cold-rolled specimen; (b) annealed at $500^{\circ} \mathrm{C}$ for $3 \mathrm{~h}$; (c) enlarged central region of (b); (d) enlarged central region near the rolling surface of (b); and (e) annealed at $500{ }^{\circ} \mathrm{C}$ for $24 \mathrm{~h}$. 


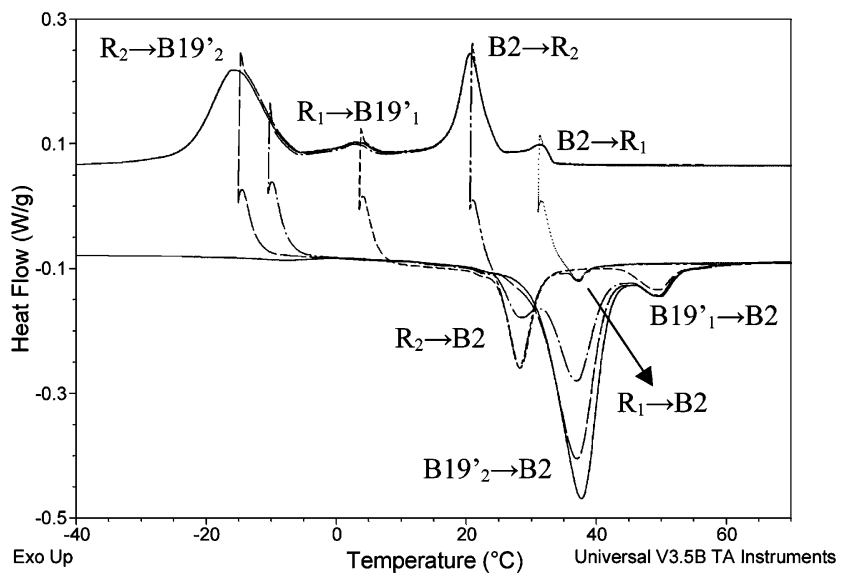

Fig. 4. Overlapped partial DSC cycles for cold-rolled $\mathrm{Ti}_{50} \mathrm{Ni}_{50}$ alloy annealed at $500{ }^{\circ} \mathrm{C}$ for $3 \mathrm{~h}$.

and we interrupt the cooling process at each transformation peak and immediately heat the specimen up to obtain the corresponding DSC heating curve. As shown in Fig. 4, the solid line represents the full DSC cycle, and the dotted line represents the DSC cycle which was interrupted at the first transformation peak (about $31.3{ }^{\circ} \mathrm{C}$ ), and a new peak appears at $37.1^{\circ} \mathrm{C}$ on heating which is not found in the full cycle. These two peaks are typical $\mathrm{B} 2 \leftrightarrow \mathrm{R}_{1}$ due to their small hysteresis transformation temperature (about $6{ }^{\circ} \mathrm{C}$ ) and small transformation enthalpies (about $1.4 \mathrm{~J} / \mathrm{g}$ ). Since the transformation enthalpies are lower than the normal values, $5 \mathrm{~J} / \mathrm{g}$ [12], it is concluded that the transformation only takes place in a relatively small volume of the specimen. When the specimen is cooled to the second transformation peak, a peak appears at $28.2^{\circ} \mathrm{C}$ on heating. Subsequently a $\mathrm{R}_{1} \rightarrow \mathrm{B} 2$ transformation peak occurs at $37.5^{\circ} \mathrm{C}$. Obviously, the new peak developed at $28.2^{\circ} \mathrm{C}$ upon heating corresponds to the second transformation peak on cooling, and therefore, together with the second peak on cooling it describes B2 $\leftrightarrow R_{2}$ transformation characterized by a small hysteresis width and small transformation enthalpies.

When the specimen is continually cooled to the third transformation peak at about $3.8^{\circ} \mathrm{C}$, there are also two peaks observed on subsequently heating. The $\mathrm{R}_{2} \rightarrow \mathrm{B} 2$ peak is still obtained at $28.3^{\circ} \mathrm{C}$ upon heating, but the $\mathrm{R}_{1} \rightarrow \mathrm{B} 2$ transformation peak at $37^{\circ} \mathrm{C}$ disappears, and another new peak appears at $49.8^{\circ} \mathrm{C}$. Therefore, the third peak on cooling can be characterized as a $\mathrm{R}_{1} \rightarrow$ $\mathrm{B} 19_{1}^{\prime}$ transformation peak because the $\mathrm{R}_{1} \rightarrow \mathrm{B} 2$ peak disappears at $37^{\circ} \mathrm{C}$ and a new $\mathrm{B} 19_{1}^{\prime} \rightarrow \mathrm{B} 2$ peak appears at $49.8^{\circ} \mathrm{C}$ on heating. When the specimen is cooled to the fourth peak, the transformation peak of $\mathrm{R}_{2} \rightarrow \mathrm{B} 2$ at $28^{\circ} \mathrm{C}$ gradually decreases and a new peak is created at about $37^{\circ} \mathrm{C}$. Consequently, the fourth peak on cooling and the new $37^{\circ} \mathrm{C}$ peak on heating represent the transformations $\mathrm{R}_{2} \rightarrow \mathrm{B} 19_{2}^{\prime}$ and $\mathrm{B} 19_{2}^{\prime} \rightarrow \mathrm{B} 2$, respectively.
All the transformations associated with the peaks shown in Fig. 4 are highlighted. From the figure, the transformation behavior of the cold-rolled and $500{ }^{\circ} \mathrm{C} \times 3 \mathrm{~h}$ annealed $\mathrm{Ti}_{50} \mathrm{Ni}_{50}$ alloy is delineated as follows. When the specimen is cooled to about $31{ }^{\circ} \mathrm{C}$, a relatively small volume transforms from $\mathrm{B} 2$ to $\mathrm{R}_{1}$ first. After being cooled to $20^{\circ} \mathrm{C}$, the untransformed $\mathrm{B} 2$ region of the specimen starts to transform from $\mathrm{B} 2$ to $R_{2}$. Both $R_{1}$ and $R_{2}$ are the premartensite $R$-phase, but they are transformed from different regions of the specimen and $\mathrm{R}_{2}$ is the dominant one. Upon the continuation of cooling down to $3{ }^{\circ} \mathrm{C}, \mathrm{R}_{1}$ transforms to $\mathrm{B} 19_{1}^{\prime}$. After the temperature is cooled to $-16{ }^{\circ} \mathrm{C}$, the dominant $\mathrm{R}_{2}$ transforms to $\mathrm{B} 19_{2}^{\prime}$. Both $\mathrm{B} 19_{1}^{\prime}$ and $\mathrm{B} 19_{2}^{\prime}$ are the monoclinic martensite, but they are transformed from $\mathrm{R}_{1}$ and $\mathrm{R}_{2}$, respectively. During the reverse transformation on heating, B19 ${ }_{2}^{\prime}$ and $\mathrm{B} 19_{1}^{\prime}$ transform back to $\mathrm{B} 2$ at $37^{\circ} \mathrm{C}$ and $50^{\circ} \mathrm{C}$, respectively. The above discussion indicates that two pairs of $\mathrm{B} 2 \rightarrow \mathrm{R} \rightarrow \mathrm{B} 19^{\prime}$ occur on cooling and two pairs of $\mathrm{B} 19^{\prime} \rightarrow \mathrm{B} 2$ appear on heating.

\subsubsection{DMA results}

From Fig. 2(b), four tan $\delta$ peaks at $18.1^{\circ} \mathrm{C}, 4.5^{\circ} \mathrm{C}$, $-7.2{ }^{\circ} \mathrm{C}$ and $-23.4{ }^{\circ} \mathrm{C}$ correspond with four DSC transformation peaks in Fig. 2(a). It was reported that the internal friction, $Q^{-1} / \tan \delta$, of $\mathrm{R} \leftrightarrow \mathrm{B} 19^{\prime}$ transformation is much larger than that of the $\mathrm{B} 2 \leftrightarrow \mathrm{R}$ transformation at the same strain amplitude and frequency [13]. From Section 4.1.1, peaks at $18.1{ }^{\circ} \mathrm{C}$ and $4.5^{\circ} \mathrm{C}$ in Fig. 2(b) are associated with $\mathrm{B} 2 \mathrm{R}$ and peaks at $-7.2^{\circ} \mathrm{C}$ and $-23.4^{\circ} \mathrm{C}$ are attributed to $\mathrm{R} \rightarrow \mathrm{B} 19^{\prime}$. Peak at $-23.4^{\circ} \mathrm{C}$ is much larger than that at $4.5^{\circ} \mathrm{C}$ and peak at $-7.2^{\circ} \mathrm{C}$ is also much larger than that at $18.1^{\circ} \mathrm{C}$. Therefore, the DMA result of Fig. 2(b) also provides more evidence to support the four-stage MST which is comprised of two pairs of $\mathrm{B} 2 \mathrm{R} \rightarrow \mathrm{B} 19^{\prime}$ on cooling, as identified in Section 4.1.1 by DSC result.

\subsection{Reasons causing the four-stage MST in a cold-rolled and annealed $\mathrm{Ti}_{50} \mathrm{Ni} i_{50}$ alloy}

The reasons for the MST behavior in Ni-rich TiNi alloys have been widely discussed, and a common conclusion of this complex MST is related to the inhomogeneous formation of aging-induced $\mathrm{Ti}_{3} \mathrm{Ni}_{4}$ precipitates. However, in this study, no $\mathrm{Ti}_{3} \mathrm{Ni}_{4}$ particles precipitate in the equiatomic $\mathrm{Ti}_{50} \mathrm{Ni}_{50}$ specimen. Consequently, the influence of $\mathrm{Ti}_{3} \mathrm{Ni}_{4}$ precipitates and their heterogeneous precipitation on the MST behavior should be excluded.

From the DSC and DMA results in this study, the four-stage MST can only be observed in some specific annealing conditions, for example annealing at $500{ }^{\circ} \mathrm{C} \times 1 \mathrm{~h}, 500{ }^{\circ} \mathrm{C} \times 3 \mathrm{~h}$ and $650^{\circ} \mathrm{C} \times 90 \mathrm{~s}$. As mentioned in Section 4.1, the four-stage MST on cooling comprises two pairs of $\mathrm{B} 2 \rightarrow \mathrm{R} \rightarrow \mathrm{B} 19^{\prime}$ transforma- 
tions. OM observations in Fig. 3 show that the grain size distribution along the specimen's thickness direction is inhomogeneous, in which the grain size at the central region is apparently larger than that near the rolling surface due to the cold-rolling effect. This implies that the four-stage MST, i.e. the two pairs of $\mathrm{B} 2 \rightarrow \mathrm{R} \rightarrow \mathrm{B} 19^{\prime}$ transformations, comes from the $\mathrm{B} 2 \rightarrow \mathrm{R} \rightarrow \mathrm{B} 19^{\prime}$ transformations of grains in the central region and those of grains near the rolling surface.

In order to clarify the effect of grain size on the MST, the specimen shown in Fig. 3(b) is ground from the bottom rolling surface to remove the smaller grains in one rolling side. At the same time, the larger grains in the central region are also ground. The thickness of the specimen is now reduced from $1.2 \mathrm{~mm}$ to $0.4 \mathrm{~mm}$. DSC test has been conducted on this ground specimen, and the result is shown in Fig. 5. Fig. 5(a) is the same specimen as Fig. 1(d), and Fig. 5(b) is the same specimen as Fig. 5(a), but now has been ground to $0.4 \mathrm{~mm}$ thickness. From Fig. 5(b), one can find that two small transformation peaks disappear, providing the evidence that the four-stage MST is associated with the small and large grains induced by the severely cold-rolled and annealed $\mathrm{Ti}_{50} \mathrm{Ni}_{50}$ alloy. In other words, in Fig. 5(a), two small peaks on cooling are associated with $\mathrm{B} 2 \rightarrow$ $\mathrm{R} \rightarrow \mathrm{B} 19^{\prime}$ caused by large grains in the central region of the specimen, but two large peaks on cooling, although they are also associated with $\mathrm{B} 2 \rightarrow \mathrm{R} \rightarrow \mathrm{B} 19^{\prime}$, are caused from small grains near the rolling surface of the specimen.

The reason why the transformation peaks corresponding to larger grains are smaller than those corresponding to smaller grains comes from the fact that the volume of large grains in the central region is less than that of small grains near the rolling surface. This is because the thickness of large grains in the specimen center is only about $50-100 \mu \mathrm{m}$, which is comparatively less than the whole specimen thickness of about $1200 \mu \mathrm{m}$.

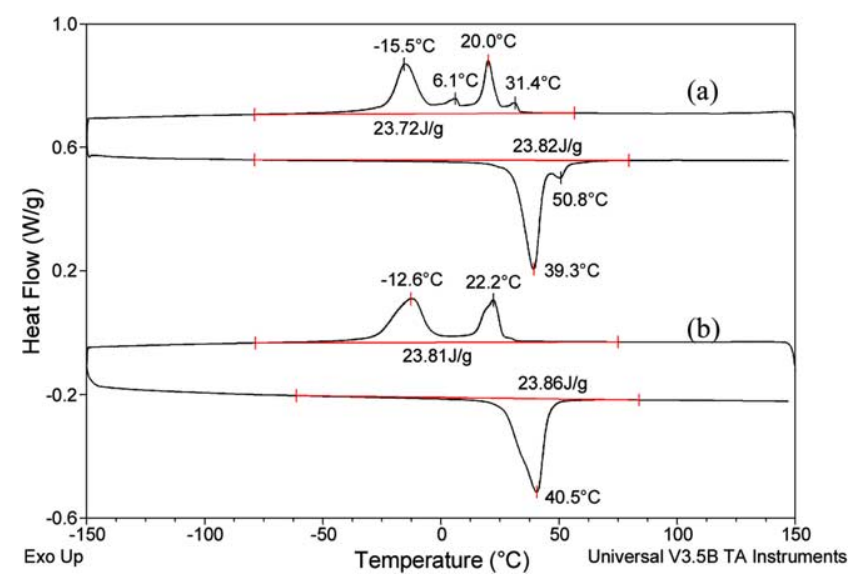

Fig. 5. DSC curves for cold-rolled $\mathrm{Ti}_{50} \mathrm{Ni}_{50}$ alloy annealed at $500{ }^{\circ} \mathrm{C}$ for $3 \mathrm{~h}$ : (a) original specimen with $1.2 \mathrm{~mm}$ thickness (the same as Fig. $1(\mathrm{~d})$ ); (b) ground specimen to $0.4 \mathrm{~mm}$ thickness.
From the viewpoint of the cold-rolling effect, the degree of plastic deformation at the specimen center should be much less than the $35 \%$ thickness reduction of the whole specimen. As a result, the recrystallized grains in the central region should be larger than those near the rolling surface under the same annealing condition. At the same time, defects and dislocations induced by the severe coldrolling of grains near the specimen's surface should be much more than those in the center. It is well known that these cold-rolling induced defects/dislocations can suppress premartensitic and martensitic transformations to lower temperatures [9]. Therefore, $\mathrm{B} 2 \rightarrow \mathrm{R}$ and $\mathrm{R} \rightarrow$ $\mathrm{B} 19^{\prime}$ transformations corresponding to small grains on cooling take place at lower temperatures than those corresponding to large grains, as shown in Fig. 5.

\section{Conclusions}

The transformation behavior of $\mathrm{Ti}_{50} \mathrm{Ni}_{50}$ shape memory alloy after $35 \%$ cold-rolling and subsequent recrystallization annealing is investigated in this study. The four-stage MST appears at specific annealing conditions having two large and two small peaks in the cooling curves of DSC and DMA $\tan \delta$ tests. Microstructural observations reveal that the grain size distribution along the specimen's thickness direction is inhomogeneous due to the cold rolling effect, in which the grain size at the central region is apparently larger than that near the rolling surface. Two small peaks in four-stage MST are related to the $\mathrm{B} 2 \rightarrow \mathrm{R} \rightarrow \mathrm{B} 19_{1}^{\prime}$ transformations of large grains and two large peaks are also associated with the $\mathrm{B} 2 \rightarrow \mathrm{R} \rightarrow \mathrm{B} 19^{\prime}$ transformations, but now they correspond to small grains near the rolling surface. The volume of large grains in the specimen center is much less than that of small grains near the rolling surface. This feature accounts for the appearance of two small and two large peaks on cooling.

\section{Acknowledgement}

The authors gratefully acknowledge the financial support for this research provided by the National Science Council (NSC), Taiwan, Republic of China, under Grants NSC92-2216-E002-008.

\section{References}

[1] Wayman CM, During TW. In: During TW, Melton KN, Stöckel D, Wayman CM, editors. Engineering aspects of shape memory alloys. London: Butterworth-Heinemann; 1990. p. 3-20.

[2] Wu SK, Lin HC, Chou TS. Acta Metall Mater 1990;38:95.

[3] Bataillard L, Gotthardt R. J Phys III 1995;5:C8-C647.

[4] Bataillard L, Bidaux J-E, Gotthardt R. Philos Mag 1998;78:327.

[5] Khalil-Allafi J, Dlouhy A, Eggeler G. Acta Mater 2002;50:4255. 
[6] Su PC, Wu SK. Acta Mater 2004;52:1117.

[7] Kim JI, Liu Y, Miyazaki S. Acta Mater 2004;52:487.

[8] ASTM Standards - Standards test method for determining average grain size. Annual book of ASTM standards, vol. 03.01. 2003. p. 256.

[9] Khelfaoui F, Guénin G. Mater Sci Eng A 2003;355:292.
[10] Thoma PE, Kao MY, Fariabi S, AbuJudom DN. In: Proceedings of ICOMAT 92. p. 917.

[11] Treppmann D, Hornbogen E, Wurzel D. In: Proceedings of ICOMAT 95. p. C8-569.

[12] Lin HC, Wu SK. Scripta Metall Mater 1991;25:1295.

[13] Lin HC, Wu SK, Yeh MT. Metall Trans A 1993;24:2189. 